\section{What is Clinical Empathy?}

Jodi Halpern, MD, PhD
Patients seek empathy from their physicians. Medical educators increasingly recognize this need. Yet in seeking to make empathy a reliable professional skill, doctors change the meaning of the term. Outside the field of medicine, empathy is a mode of understanding that specifically involves emotional resonance. In contrast, leading physician educators define empathy as a form of detached cognition. In contrast, this article argues that physicians' emotional attunement greatly serves the cognitive goal of understanding patients' emotions. This has important implications for teaching empathy.

J GEN INTERN MED 2003;18:670-674.

$\mathbf{T}$ here is a long-standing tension in the physician's role. On the one hand, doctors strive for detachment to reliably care for all patients regardless of their personal feelings. Yet patients want genuine empathy from doctors, and doctors want to provide it. ${ }^{1,2}$ Medical educators and professional bodies increasingly recognize the importance of empathy, but they define empathy in a special way to be consistent with the overarching norm of detachment. Outside the field of medicine, empathy is an essentially affective mode of understanding. Empathy involves being moved by another's experiences. In contrast, a leading group from the Society for General Internal Medicine defines empathy as "the act of correctly acknowledging the emotional state of another without experiencing that state oneself."3

It goes without saying that physicians cannot fully experience the suffering of each patient. However, the point of saying that the physician does not "experience that state oneself" is, presumably, to emphasize that empathy is an intellectual rather than emotional form of knowing. This assumes that experiencing emotion is unimportant for understanding what a patient is feeling.

Received from the Division of Health and Medical Sciences, University of California, Berkeley-Berkeley, Calif.

The author thanks Oxford University Press for permission to use material from Halpern J, From Detached Concern to Empathy: Humanizing Medical Practice, Oxford University Press, 2001.

Address correspondence and requests for reprints to Dr. Halpern: Division of Health and Medical Sciences, University of California-Berkeley, 570 University Hall \#1190, Berkeley, CA 94720-1190 (e-mail: jhalpern@socrates.berkeley.edu).
This recent definition is consistent with the medical literature of the twentieth century, which defines a special professional empathy as purely cognitive, contrasting it with sympathy. Sympathetic physicians risk overidentifying with patients. Further, all emotional responses are seen as threats to objectivity. Influential articles in the The New England Journal of Medicine and the Journal of the American Medical Association in the 1950s and 1960s argue that clinical empathy should be based in detached reasoning. ${ }^{4,5}$ Blumgart, for example, describes "neutral empathy," which involves carefully observing a patient to predict his responses to his illness. The "neutrally empathetic" physician will do what needs to be done without feeling grief, regret, or other difficult emotions. ${ }^{4}$

Blumgart's description recalls the early twentiethcentury writings of Sir William Osler. In his 1912 essay, "Aequanimitas," Osler argues that by neutralizing their emotions to the point that they feel nothing in response to suffering, physicians can "see into" and hence "study" the patient's "inner life."6 This visual metaphor of projecting the patient's "inner life" before the physician's mind's eye underscores the stance of detachment. Viewers stand apart from what they observe. This contrasts markedly with the ordinary meaning of empathy as "feeling into" or being moved by another's suffering.

The concept of a detached physician accurately viewing a patient's emotions persists throughout the twentieth century. In their classic 1963 article, "Training for Detached Concern," Fox and Lief describe how physicians believe that the same detachment that enables medical students to dissect a cadaver without disgust allows them to listen empathically without becoming emotionally involved. ${ }^{7}$

\section{DETACHED CONCERN IS NOT THE SAME AS EMPATHY}

Physicians recognize that they cannot genuinely overcome all emotions. Yet, they strive to view patients' emotions objectively. The model of detached concern presupposes that knowing how the patient feels is no different from knowing that the patient is in a certain emotional state. When used to refer to impersonal knowledge about a state of affairs, such as the workings of bodies, the term "knowing how" is interchangeable with the term "knowing that." Knowing how the stomach puts out gastric acid is the same as knowing that histamine cells stimulate the release of certain hormones. Accordingly, 
knowing how a patient feels would be the same as knowing that, in fact, she is sad versus anxious.

However, the function of empathy is not merely to label emotional states, but to recognize what it feels like to experience something. That is why empathy is needed even when it is quite obvious what emotion label applies to a patient. Consider the following example of mine from several years ago. The medical team called for psychiatry to consult on a patient with Guillan-Barre syndrome who was depressed and refusing treatment. When I first came into the patient's room, I noticed a flicker of interest in his eyes as he greeted me. He was completely paralyzed from the neck down. He greeted me by struggling to whisper a few words through his tracheotomy tube. The nurse gently adjusted his tube. I felt uncomfortable viewing his immobile body splayed on the bed, hearing him struggle.

I spoke to him in a quiet, gentle way. As I spoke, he became withdrawn, literally looking away to end the conversation. I felt ashamed at imposing on him. Yet, when I thought about the shame, which led me to retreat, I wondered if this shame was also an emotion that came from resonance with him. Here he was, a powerful man, now suddenly paralyzed and exposed to all of his caregivers. My gentle approach to him clearly backfired-did he sense pity? I tried to change my tone, to see how he responded. I asked him, directly and assertively, what was bothering him about how we were treating him. He looked right at me and then began an angry tirade about how disrespected he felt. This engagement was the beginning of an effective therapeutic alliance.

In another incident, reported by a pregnant patient to me, a physician discussed with her what she might expect during labor and delivery. Noting that the woman seemed anxious, he immediately reassured her that she had options for pain relief, and went into a detailed exposition of these options. He noted afterward that the patient was still anxious, and asked her directly what was making her anxious. Despite recognizing her physician's sincere concern, the patient did not answer, and changed obstetricians.

According to the patient, she felt increasingly panicked as the doctor tried to reassure her about pain relief, hearing about being "tied" to an intravenous line, and then about how she might feel numbness and be unable to push secondary to medication. This patient had been a rape victim, and deeply feared being restrained and losing control. She believed that by the doctor continuing on and on in a cheerful way as he described these options, he signaled to her that he did not recognize how terrified she felt. His reassurances felt generic, and she did not feel able to express her fear without him pausing and recognizing her in some nonverbal way.

What is fascinating about juxtaposing these 2 cases is that in both, the physicians are genuinely concerned about the patients and ask essentially the same questions. Yet, in the former case, emotional attunement guides the timing and tone, whereas in the latter, this appears not to be the case. A recent study reported in the Journal of the American
Medical Association observed patient-physician interactions and noted that nonverbal attunement led physicians to pause at moments of heightened anxiety, at which times patients disclosed information. If physicians did not do this, patients did not share vulnerable information, despite the physicians asking the patients appropriate and accurate questions. ${ }^{8}$

This study reminded me that as a beginning psychotherapist I learned to avoid directly asking "how are you feeling?" because people rarely gave full responses. Instead, I learned to trust my own emotional cues to shifts in patient's emotions to guide me to pause silently or repeat a few of their words when I sensed anxiety or sadness. Patients told me much more.

\section{SPECIFIC WAYS THAT EMOTIONS CONTRIBUTE TO EMPATHY}

The importance of nonverbal attunement seriously undermines the "detached concern" model of empathy. However, what remains to be clarified is what exactly such attunement involves. If engaged empathy (herein referred to simply as empathy) requires experiencing emotions in parallel with each patient, this would be absurdly demanding (even for psychotherapists). Further, general internists do not have the time that psychotherapists do to focus on emotions.

One key point of this article is that empathy does not require that physicians vicariously experience and introspect about patients' emotions. The physician's attention should not be unduly diverted to introspection. The whole point of empathy is to focus attention on the patient. A listener who was busy having his or her own parallel emotions and introspecting about them would have the wrong focus.

Emotional attunement operates by shaping what one imagines about another person's experience. In trying to imagine what the patient is going through, physicians will sometimes find themselves resonating. This is not an additional activity to imagining, but rather a kind of involuntary backdrop to it. Further, resonance is not a special professional skill, but a part of ordinary communication. While listening to an anxious friend, one becomes anxious, while talking with a coworker, one feels heavy, depressed feelings. Importantly, attuning to patients does not always involve resonating with strong feelings, but often is a subtle nonverbal sense of where another person is emotionally.

The special professional skill of clinical empathy is distinguished by the use of this subjective, experiential input for specific, cognitive aims. Empathy has as its goal imagining how it feels to be in another person's situation. Outside medicine, imagining how an experience feels is similar to daydreaming or fantasizing. An emotion or mood sets the tone of the imagined scenario. In clinical practice, the challenge is to use skillful attunement, not in leisurely fantasy, but in multiple, rapid, ordinary clinical 
interactions. For example, if a patient says that she has stopped taking her medication, empathy involves taking cues from her tone. This patient may be angry about sexual side effects, or she may be upbeat, and see the medication as unnecessary because she doesn't feel sick, or she may see the medication as useless because she feels hopeless about getting well. In each case, addressing the patient more or less appropriately depends upon attuning to the patient's emotions.

At this point, the busy physician reader might be wondering about the clinical utility of empathy when a physician can do a quick checklist review and cover the common reasons people stop taking medications. I do not disagree with this point. Most likely, there is no single question for which physicians need empathy to get an answer. Yet in the daily grind of medical practice, an empathic physician gains a source of information that is at least as efficient as having checklists for each psychological need of patients. Here are 4 ways that physicians can capitalize on their emotional responses to enhance medical care.

\section{Empathy Involves Associative Reasoning}

First, emotional attunement helps physicians appreciate the personal meanings of patients' words. Emotions guide thought by linking one idea to another in an "associative" way: in addition to thinking logically, we link ideas that have affective, sensory, and experiential similarities. What doctors say to patients has associative as well as logical meanings. For example, a patient may take the term "degenerative joint disease" to signify that she is falling apart. Of course, a detached physician can recognize this meaning of the word degenerative. Yet an emotionally attuned doctor has an additional source of noticing which words are particularly loaded for a particular patient. Alongside the logical meanings conveyed in conversations is an ongoing flow of associative or emotional meanings. By attuning to another person, one follows this flow with much more ease than if one were to try to get at all this meaning through asking questions and consulting checklists. (Gleaning meanings by associating involves all kinds of inaccuracies, so that at some point the doctor needs to check his or her understanding with the patient more directly.)

Associative listening need not be an added task. Physicians can make use of what they already notice but have learned not pay attention to. For example, a patient suddenly refused previously wanted life-sustaining treatment. She wouldn't talk to anyone, and wanted to be sedated and never wake up. She wound up telling me her painful story, but then became angry and said that asking her to talk was "the cruelest thing anyone had ever done" to her. Her striking words were an important clue to what I learned about her situation. Just a few days before, when she had just gotten out of surgery, her husband of many years had told her that he was leaving her. Patients' words communicate meanings that cannot be summarized on a preformed checklist.

\section{Emotions Help Guide and Hold Attention on What is Humanly Significant}

Second, physicians' emotions focus and hold their attention on what the patient is anxious about. Consider a physician who sees a patient who suffers from headaches and fatigue. When asked about her home life, the patient says that everything is fine. Yet, something about the patient's body language, perhaps an evasive gaze, worries the physician. By resonating with the patient's anxiety, the physician is more likely to slow down at this point in the history and gather more information.

The skeptic might ask, can't a detached but thorough physician notice the patient's gaze? The answer is yes, of course. However, it would be difficult for even the most thorough but nonintuitive physician to consciously observe and attend to the dozens of signals that have emotional import in each patient interview. Emotional attunement spontaneously directs attention to some aspects of patient's histories over others.

Neuroscientist Antonio Damasio ${ }^{9}$ and philosopher Ronald de Sousa ${ }^{10}$ describe this focusing and riveting of attention as necessary because human beings are so cognitively complex that events in daily life involve too many possible things to pay attention to. The cognitive tasks physicians face are at least as complex as the tasks of daily life, and logic alone cannot determine which matters are most important to pay attention to. Nonverbal attunement automatically directs attention to matters that have emotional significance to the patient. Of course, such intuitions in no way supplant thorough history taking and paying attention to other clinical clues. Rather, resonance offers short cuts, the paths of which still need to be rechecked in a systematic way.

\section{Empathy Facilitates Trust and Disclosure and Can Be Directly Therapeutic}

A third related contribution of empathy is that it facilitates patient trust and disclosure. Physicians express empathy not only by grasping the personal meanings of patients' words, but also by (automatically) matching patients' nonverbal style, for example, their vocal tones. When doctors attune to patients nonverbally, patients feel more comfortable and give fuller histories. ${ }^{8}$

Further, there is a growing body of evidence suggesting that empathy directly enhances therapeutic efficacy. Engaged communication has been linked to decreasing patient anxiety, ${ }^{11,12}$ and, for a variety of illnesses, decreasing anxiety has been linked to physiologic effects and improved outcomes. ${ }^{12,13}$ An expert panel on how physicians deliver bad news concluded that patients cope better in the long term if their doctors are empathic. ${ }^{14}$

The skeptic might ask why it matters whether physicians respond emotionally if they just behave empathically. My response to this is threefold: 1) The observational studies mentioned above show that patients sense whether physicians are emotionally attuned. ${ }^{8}$ 2) Patients trust physicians 
who respond to their anxiety with their own responsive worry. Trust has been associated with better treatment adherence. ${ }^{15}$ 3) It matters when and how physicians ask patients about their feelings, and empathic attunement guides physicians about when to ask questions, when to stay silent, and when to repeat important words.

\section{Empathy Makes Being a Physician More Meaningful and Satisfying}

Finally, empathy makes practicing medicine more meaningful. Many physician narratives attest to this. There is also some research supporting this claim, although there are alternative hypotheses that could explain the findings. For example, Roter et al. found that physicians with an engaged, psychosocially oriented communication style burn out less frequently than others. ${ }^{16}$ Robert Coles, writing about William Carlos Williams as well as himself, says that during moments of empathic connection, the real meaning of medical practice is suddenly illuminated in terms of hidden personal meanings. ${ }^{17}$ Physicians who allow their patients to move them enrich their own experience of doctoring.

\section{IS EMPATHY PRACTICAL?}

In conclusion, empathy is an experiential way of grasping another's emotional states. Empathy is a "perceptual" activity that operates alongside logical inquiry. So long as physicians continue to exercise their skills of objective reasoning to investigate their empathic intuitions, empathy should enhance medical diagnosis rather than detract from it. Further, empathy enhances patient-physician communication and trust, and therefore treatment effectiveness.

Once empathy is seen as depending on emotional responses, however, a critical problem arises. Emotions are generally outside people's immediate control. How can physicians reliably empathize with patients toward whom they naturally feel little or even negative emotions? Sometimes emotional resonance comes easily. However, busy, overworked physicians may find such responses absent.

One path to educating empathic physicians is by encouraging trainees to maintain their natural curiosity about their patients' lives. ${ }^{18}$ Doctors learn to suppress curiosity in order to take rapid, standardized histories. Charon, Coles, and others have fostered curiosity by encouraging trainees to hear and then tell patients' firstperson accounts of illness. ${ }^{17,19}$ Once busy in practice, physicians previously trained to write narrative histories might listen more precisely to patients' words. The previously mentioned patient who was paralyzed told me that his treatments were "useless, a waste." Repeating these words moved him to tears and moved me to imagine that he felt his own life had become "useless, a waste."

There are several barriers to empathy. First, anxiety interferes with empathy. Time pressure is invoked as a concrete barrier to listening to patients, but probably functions more as a psychological barrier, making physi- cians anxious. This can be addressed in part by showing physicians that listening can make care more efficient. For example, it usually takes less than ninety seconds for a patient to speak without interruption at the beginning of an interview, and this helps set the tone for trust and disclosure. ${ }^{20}$ More generally, to address the anxieties that accompany doctoring, the culture of detachment needs to shift, encouraging physicians to acknowledge and seek support for their own emotional needs.

A second barrier to empathy is that many physicians still do not see patients' emotional needs as a core aspect of illness and care. Research shows that doctors who regularly include the psychosocial dimensions of care communicate better overall. Physicians can be educated to perceive psychosocial needs as important. ${ }^{21}$

A third barrier to empathy comes from the negative emotions that arise when there are tensions between patients and physicians. Physicians who feel angry with patients and yet find such feelings unacceptable face barriers to thinking about the patient's perspective. All physicians could be taught to tolerate and learn from their own negative feelings in the way psychiatry residents are taught to pay attention to counter-transference. ${ }^{22-24}$ We need both theoretical and empirical work to address such barriers and to help elucidate the intermediary steps that physicians can take to practice medicine with genuine empathy.

The author gratefully acknowledges Helaina Kravitz, MD, for advice and comments on this work.

\section{REFERENCES}

1. Learning objectives for medical student education-guidelines for medical schools: Report I of the Medical School Objectives Project. Acad Med. 1999;74:13-8.

2. Bertakis KD, Roter D, Putnam SM. The relationship of physician medical interview style to patient satisfaction. J Fam Pract. 1991;32:175-81.

3. Markakis K, Frankel R, Beckman H, Suchman A. Teaching empathy: it can be done. Working paper presented at the Annual Meeting of the Society of General Internal Medicine, San Francisco, Calif, April 29-May 1, 1999.

4. Blumgart H. Caring for the patient. N Engl J Med. 1964;270: 449-56.

5. Aring C. Sympathy and empathy. JAMA. 1958;167:448-52.

6. Osler W. Aequanimitas. New York, NY: Norton; 1963:29.

7. Fox R, Lief H. Training for "detached concern." In: Lief H, ed. The Psychological Basis of Medical Practice. New York, NY: Harper \& Row; 1963.

8. Suchman A, Markakis K, Beckman H, Frankel R. A model of empathic communication in the medical interview. JAMA. 1997; 277:678-82.

9. Damasio A. Descartes' Error. London, UK: Macmillan; 1994.

10. De Sousa R. The Rationality of Emotions. Cambridge, Mass: MIT Press; 1987.

11. Butow P, Maclean M, Dunn S, Tattersall M, Boyer M. The dynamics of change: cancer patients' preferences for information, involvement and support. Ann Oncol. 1997;8:857-63.

12. Rietveld S, Prins P. The relationship between negative emotions and acute subjective and objective symptoms of childhood asthma. Psychol Med. 1998;28:407-15. 
13. Frasure-Smith N, Lesperance F, Talajic M. The impact of negative emotions on prognosis following myocardial infarction: is it more than depression? Health Psychol. 1995;14:388-98.

14. Girgis A, Sanson-Fisher R. Breaking bad news: consensus guidelines for medical practitioners. J Clin Oncol. 1995;13: 2449-56.

15. Roter D, Hall J, Merisca R, Nordstrom B, Cretin D, Svarstad B. Effectiveness of interventions to improve patient compliance: a meta-analysis. Med Care. 1997;36:1138-61.

16. Roter D, Stewart S, Putnam N, Lipkin M. Communication patterns of primary care physicians. JAMA. 1997;277:350-6.

17. Coles R. The Call of Stories. Boston, Mass: Houghton Mifflin; 1989: 117-8.

18. Brody H. The Healer's Power. New Haven, Conn: Yale University Press; 1992.
19. Charon R. Narrative medicine: a model for empathy, reflection, profession and trust. JAMA. 2001;286:1897-902.

20. Langewitz W, Denz M, Keller A, Kiss A, Ruttimann S, Wossmer B Spontaneous talking time at start of consultation in outpatient clinic: cohort study. BMJ. 2002;325:682-3.

21. Levinson W, Roter D. Physicians' psychosocial beliefs correlate with their patient communication skills. J Gen Intern Med. 1995;10: 375-9.

22. Vanderford M, Stein T, Sheeler R, Skochelak S. Communication challenges for experienced clinicians: topics for an advanced communication curriculum. Health Commun. 2001;13:261-84.

23. Stein H. The Psychodynamics of Medical Practice. Berkeley, Calif: University of California Press; 1985.

24. Winnicott D. Hate in the counter-transference. Int J Psychoanal. 1949;30:69-74.

ANNOUNCEMENT

JGIM Website — Visit us online today!

Please visit the JGIM World-Wide Website:

http://www.blackwellscience.com/journals 